\title{
Application of surface enhanced Raman scattering to the solution based detection of a popular legal high, 5,6-methylenedioxy-2-aminoindane (MDAI) $\dagger$
}

Cite this: DOI: 10.1039/c5an00591d

\author{
Samuel Mabbott, ${ }^{a, b}$ Omar Alharbi, ${ }^{a}$ Kate Groves ${ }^{a}$ and Royston Goodacre ${ }^{a}$
}

The ever increasing numbers and users of designer drugs means that analytical techniques have to evolve constantly to facilitate their identification and detection. We report that surface enhanced Raman scattering (SERS) offers a relatively fast and inexpensive method for the detection of MDAI at low concentrations. Careful optimisation of the silver sol, and salt concentrations was undertaken to ensure the SERS analysis was both reproducible and sensitive. The optimised system demonstrated acceptable peak variations of less than $15 \%$ RSD and resulted in a detection limit of just $8 \mathrm{ppm}\left(5.4 \times 10^{-5} \mathrm{M}\right)$.

Received 25th March 2015, Accepted 5th May 2015

DOI: $10.1039 / c 5 a n 00591 d$

www.rsc.org/analyst
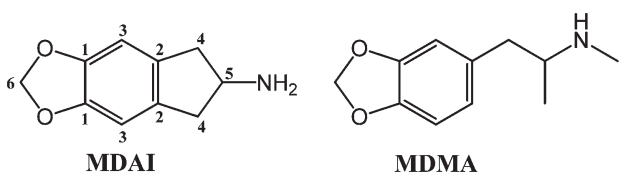

reational usage of legal highs. ${ }^{1-3}$ These synthetic derivatives of banned substances such as MDMA and amphetamines have flooded the drugs market, often the derivatives provide a cheaper alternative to illegal substances. Legal highs have the potential to cause major health risks, due to little knowledge of the chemicals they contain and lack of information about human consumption. Furthermore, whilst short-term side effects are easily documented little is known about the effects of their long-term usage. Accessibility of the drugs over the internet and in so called 'headshops', also makes them an attractive option for users, although sale of the drugs is normally considered illegal under the medicines legislation act. ${ }^{22}$ This is why many sellers of the 'highs' often advertise them as bath salts or plant food (not for human consumption). In the UK alone it has been reported that 150 new legal highs were in circulation in the three years between 2010 and 2013. ${ }^{24}$ Popular 'highs' being sold over the internet include 5-IAI (5iodo-2-aminoindane), ${ }^{4}$ Benzofury (6-(2-aminopropyl)benzofuran $)^{5}$ and MDAI (5,6-methylenedioxy-2-aminoindane $)^{6,7}$ to name but a few. However, it is the latter of these drugs, MDAI (Fig. 1) which is of concern to this work. The widespread availability and recreational use of MDAI is thought to have been created via the banning of mephedrone, a cathinone deriva-

${ }^{a}$ Manchester Institute of Biotechnology, School of Chemistry, The University of

Manchester, Manchester, M1 TDN, UK

${ }^{b}$ Centre for Molecular Nanometrology, Department of Pure and Applied Chemistry, University of Strathclyde, 295 Cathedral Street, Glasgow, G1 1XL, UK

$\dagger$ Electronic supplementary information (ESI) available: Raman spectrum of MDAI powder (Fig. S1) and the SERS spectra of MDAI collected at different drug concentrations (Fig. S2). See DOI: 10.1039/c5an00591d
Fig. 1 The structure of MDAl with numbers for NMR assignment and the amphetamine MDMA.

tive, ${ }^{8,9}$ which had caught the attention of the UK media towards the end of 2009. ${ }^{10,11}$ Due to the growth in the number of users and documented ill-effects, the substance was consequently categorised as a class B drug along with other cathinone derivatives in April 2010. ${ }^{12}$ Nichols at Purdue University first synthesised MDAI in $1990,{ }^{13}$ the structural basis is similar to that of 3,4-methylenedioxy- $N$-methylamphetamine (MDMA) with the only difference between the two being that the methylpropan-2-amine moiety of MDMA is replaced with a 2-aminoindane group. MDAI has been shown to have a indistinguishable pharmacology to MDMA (Fig. 1) whose primary mechanism is to act as a selective serotonin releasing agent. ${ }^{14,15}$ It is therefore evident that like most amphetamines MDAI is taken for its entactogenic effects, which include increased levels of intimacy, consciousness and euphoria, but these effects often contradict online blogs written by the drugs users who demonstrate mixed reviews about the drug's effect. ${ }^{8}$ Most seriously however, it is believed that the first death caused by an MDAI overdose was recorded in the Isle of Man on the $15^{\text {th }}$ of April 2011. ${ }^{16}$ The development and optimisation of new and existing laboratory analytical methods is essential in order to remain up-to-date with the rapid changes in drugs culture. ${ }^{17}$ However, little analytical work to detect and establish the limit of detection of MDAI has been carried out. There 


\section{Experimental}

\section{Materials}

Silver nitrate (99.9999\%) and trisodium citrate were purchased from Sigma Aldrich (Dorset, U.K.). A $100 \mathrm{mg}$ capsule of MDAI (5,6-methylenedioxy-2-aminoindane) sold as 'Sparkle' was purchased from a 'headshop' (Dr Herman's, Manchester, U.K.). The drug contained within the capsule had a white flaky appearance. The purity of the drugs was verified via melting point tests, mass spectrometry (MS) and nuclear magnetic resonance spectroscopy (NMR). All solvents used were of analytical grade and water was HPLC certified.

\section{Methods}

Drug purity verification. Although the drug was advertised as being supplied in $100 \mathrm{mg}$ amounts, the weight of the drug without the capsule was only $73 \mathrm{mg}$ therefore the analytical techniques used to verify purity had to be selected carefully. Both MS and NMR were used to derive the structure of the drug and to ensure that no other impurities were present. The melting point tests gaves an accurate idea of the purity due to the sharpness and temperature at which the sample melted.
The values obtained from these analyses could be directly compared to the original synthesis values. ${ }^{13}$

Mass spectrometry. The samples were analysed using electrospray ionisation mass spectrometry (ESI-MS) operating in positive mode. Two peaks were identified in the spectrum at $\mathrm{m} / \mathrm{z}$ of 161 and 178 , relating to MDAI minus the protonated amine moiety and protonated MDAI respectively.

${ }^{1} \mathbf{H}$ NMR (200 MHz, D 20 ). $\delta$ 6.73, (s, 2, ArH), $5.84\left(\mathrm{~s}, 2, \mathrm{CH}_{2}\right)$, 4.05 (m, 1, CH), 3.19 (dd, 2, $2 \times \mathrm{CH}, J=15.4 \mathrm{~Hz}, 6.6 \mathrm{~Hz}), 2.84$ (dd, 2, $2 \times \mathrm{CH}, J=15.4 \mathrm{~Hz}, 5.2 \mathrm{~Hz}), 2.15$ (s, 2, $\mathrm{NH}_{2}$ ).

${ }^{13} \mathrm{C}$ NMR (300 MHz, $\mathrm{D}_{2} \mathrm{O}$ ). Bracketed numbers relate to the positions of the carbons outlined in Fig. 1.

$$
\delta 146.7 \text { (1), } 131.9 \text { (2), } 105.4 \text { (3), } 101.1(6), 52.1 \text { (5), } 36.9 \text { (4). }
$$

\section{Melting point test}

Five replicate melting point tests were carried out on $\sim 3 \mathrm{mg}$ of the drug per test. The melting point was sharp and averaged $275^{\circ} \mathrm{C}$ only $1^{\circ} \mathrm{C}$ lower than the original synthetic value. ${ }^{13}$

\section{Synthesis of silver colloids}

All glassware was cleaned using aqua regia to remove any residual trace metals. After $1 \mathrm{~h}$ of treatment the flasks were then washed with copious amounts of methanol, dried under a stream of nitrogen then rinsed with water. To ensure all the solvents had evaporated, the flasks were placed in a temperature-controlled oven $\left(60^{\circ} \mathrm{C}\right)$ for $20 \mathrm{~min}$. Silver nanoparticles were synthesised using the Lee and Meisel method. ${ }^{23}$ Initially $\mathrm{AgNO}_{3}(90 \mathrm{mg}$ ) was dissolved in $500 \mathrm{~mL}$ of water and bought to the boil. Under vigorous stirring a $1 \%$ solution of trisodium citrate $(10 \mathrm{~mL})$ was added. The solution/sol was left to boil for $1 \mathrm{~h}$, the formation of nanoparticles was verified when the previously transparent solution developed a milky green hue. The method was replicated for the synthesis of five batches of silver colloid.

\section{UV-visible (UV-vis) absorption/extinction nanoparticle characterisation}

In order to determine the position of the plasmon band $\lambda_{\max }$ it was essential to characterise the nanoparticles using UV-vis spectrophotometry. Samples were prepared by combining 1 part silver colloid with 9 parts water. $1 \mathrm{~mL}$ of the dilute nanoparticle solution was then pipetted into a quartz cuvette and inserted into a sample holder of a Thermo Biomate 5 (Thermo Fisher Scientific Inc., Massachusetts, USA). A spectrum was collected for each of the 5 colloidal batches. Fig. 2 shows the typical UV-Vis spectra obtained whilst the table details the $\lambda_{\max }$ and full width, half maximum (FWHM) for each batch of colloid.

\section{SERS analyses}

Raman spectra were collected using a DeltaNu Advantage benchtop Raman spectrometer (Intevac inc, California, USA). The instrument is equipped with a $633 \mathrm{~nm}$ HeNe laser with a power output of $3 \mathrm{~mW}$ at sample. Spectra were collected over a range of $200-3400 \mathrm{~cm}^{-1}$ with a spectral resolution of $10 \mathrm{~cm}^{-1}$. Solution samples were placed in an $8 \mathrm{~mm}$ diameter glass vial 


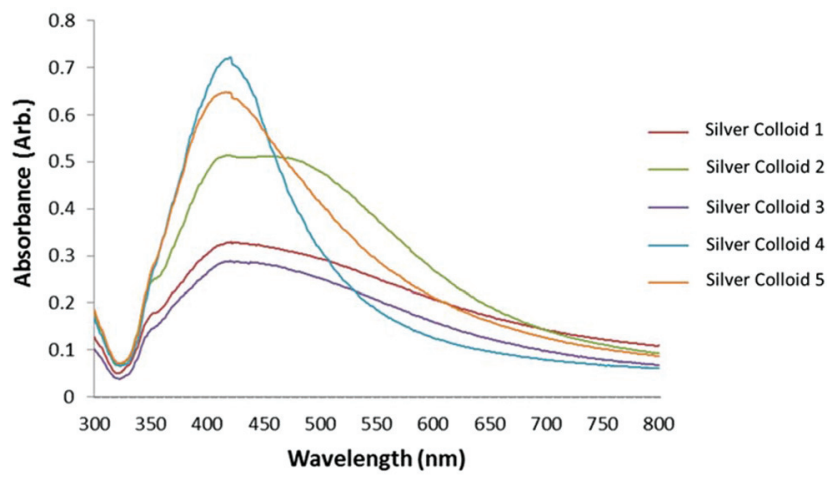

\begin{tabular}{|c|c|c|}
\hline${\text { Colloidal Batch } \mathbf{N}^{\mathbf{0}}}$ & $\boldsymbol{\lambda}_{\max }(\mathbf{n m})$ & FWHM (nm) \\
\hline 1 & 421 & 312 \\
\hline 2 & 418 & 257 \\
\hline 3 & 420 & 268 \\
\hline 4 & 420 & 122 \\
\hline 5 & 417 & 173 \\
\hline
\end{tabular}

and subjected to laser irradiation once loaded into the sample cell attachment. The instrument was calibrated to determine the optimum distance from the laser to the glass vial using toluene and polystyrene. Raman spectra of the solid MDAI sample were also taken on the same system but unfortunately the signal response was a broad and featureless (see an example spectrum in Fig. S1†). It was due to the lack of specific vibrational features and strong fluorescent background that analyses had to be carried out in solution using SERS, which is known to quench fluorescence and also enhance the Raman signature.

\section{Optimisation of aggregation}

The control of such a dynamic system present in solution based SERS is essential to ensure maximum reproducibility. One of the ways of managing reproducibility is to optimise the aggregation time. Variation in SERS signal can result from differing batches of colloids therefore 5 batches of silver colloids were synthesised and tested along with differing concentrations of $\mathrm{KNO}_{3}$ aggregating agent $(0.5 \mathrm{M}$ and $1.0 \mathrm{M})$ with a set analyte concentration of $500 \mathrm{ppm}\left(2.8 \times 10^{-3} \mathrm{M}\right)$. Although many different aggregating agents could have been used, previous experiments carried out in the group found that systems including $\mathrm{KNO}_{3}$ gave the best SERS response (data not shown). To reduce any Raman/SERS signal variability as a result of differing the volume of components, the colloid and analyte volume were kept at $200 \mu \mathrm{L}$ and aggregating agent at $50 \mu \mathrm{L}$, resulting in $450 \mu \mathrm{L}$ of experimental solution being interrogated in total. The order in which the individual components were added to the glass vial was also kept constant. Initially the colloid was added followed by the MDAI solution then the aggregating agent. To allow time for the nanoparticles and analytes to equilibrate in solution a $40 \mathrm{~min}$ lag phase was included before the aggregating agent was added. Raman spectra was collected on each of the samples over a period of $40 \mathrm{~min}$ with each spectra generated over a $30 \mathrm{~s}$ interrogation period. This resulted in 80 spectra being collected for each sample. A total of 10 samples were scrutinized. A definition of what the proposed optimum aggregation time is and the methodology for its discovery is given in the results and discussion section.

\section{Reproducibility studies}

Once the optimum aggregation time had been established for each experimental system, replicate sample reproducibility was tested. In order to do this, samples were made up exactly as outlined in the aggregation study, whilst varying the time that the samples were left to aggregate for their identified aggregation period before collecting a SERS spectrum of the sample for $30 \mathrm{~s}$. Five replicate samples from each batch of sol at the differing salt concentrations were used to assess reproducibility. A total of 50 samples were interrogated ( 5 replicates $\times 5$ colloidal batches $\times 2$ salt concentrations).

\section{Limit of detection (LOD) studies}

Once the reproducibility of the SERS systems had been assessed, the best system was used to evaluate the LOD of the drug. The drug concentrations analysed ranged from $500 \mathrm{ppm}$ $\left(2.8 \times 10^{-3} \mathrm{M}\right)$ to $1 \mathrm{ppm}\left(5.6 \times 10^{-6} \mathrm{M}\right)$. Five replicate samples were analysed at each concentration, and as before the optimised aggregation times were used. Analyte concentration did not affect the optimum aggregation time used.

\section{Results and discussion}

Optimisation of aggregation time

Aggregation of nanoparticles is essential to produce 'hot-spots' from which the Raman signal of an analyte is enhanced. The addition of a salt is a common method of inducing aggregation, however the clustering of nanoparticles needs to be controlled if the enhanced signal is to be reproducible.

The initial challenge was thus to identify the optimum aggregation. The word optimum in this instance defines the time at which the SERS signal plateaus, yielding the most reproducible SERS response The $40 \mathrm{~min}$ lag phase introduced before the addition of an aggregating agent was to allow the maximum number of MDAI molecules to associate with the nanoparticles and displace citrate molecules used to stabilise the metal entities, by doing this it was hoped that little variation and shifting of the SERS peaks would arise. Spectra generated on the DeltaNu Raman spectrometer were saved and exported in a .spc format. Data were analysed using Matlab version 2011a (The MathWorks, Inc., Natick, Massachusetts, USA). Once the spectra had been collected from the 10 SERS systems, the 80 spectra representative of each individual system were averaged, to elucidate the peak positions. A staggered plot of mean spectra for each of the colloidal batches is 

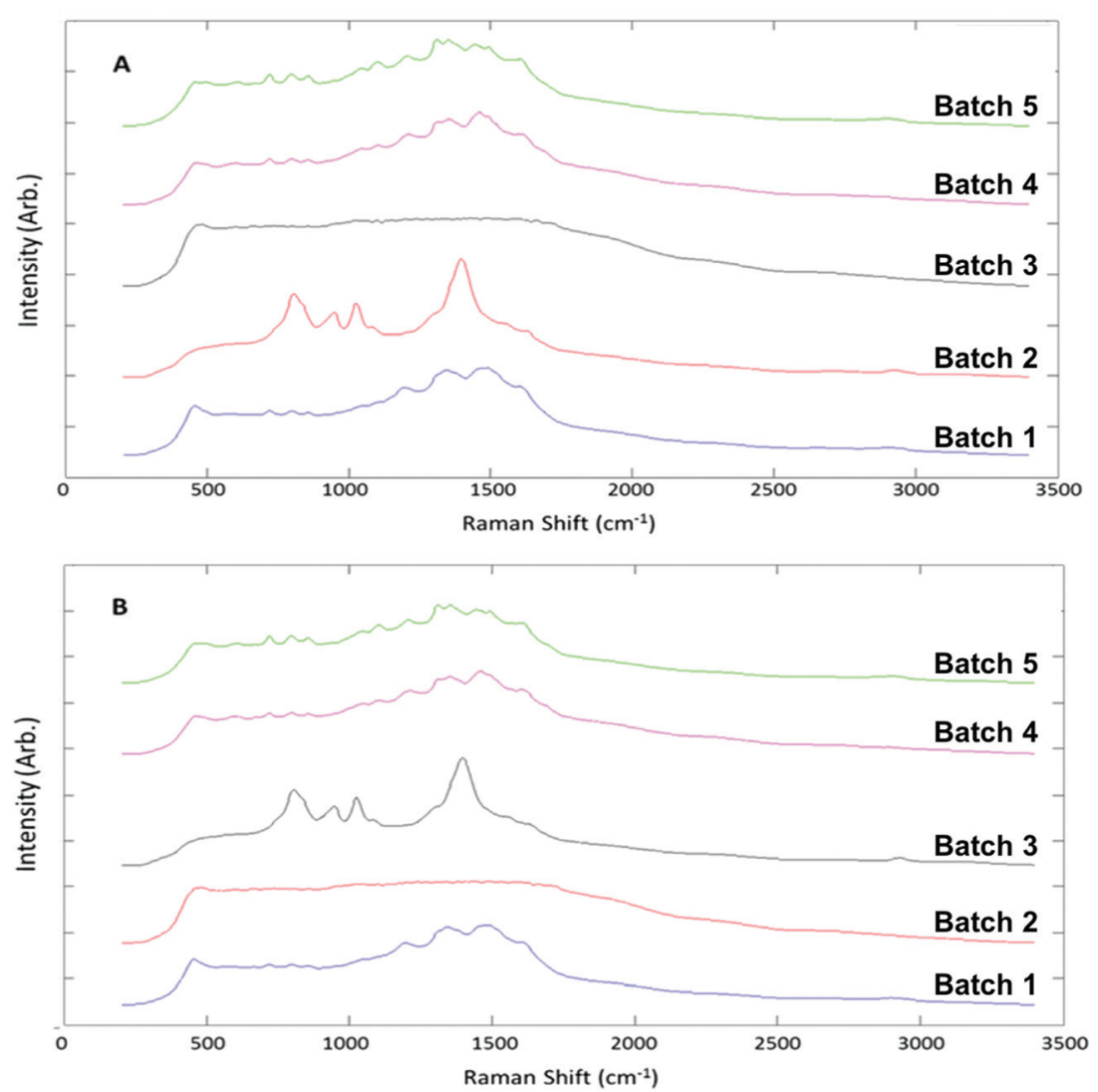

Fig. 3 Average scaled spectra of each batch of colloid generated through the optimisation of aggregation experiment. (A) Represents spectra collected using $0.5 \mathrm{M}$ aggregating agent $\left(\mathrm{KNO}_{3}\right)$ and $(\mathrm{B})$ represents spectra collected using $1 \mathrm{M}$ aggregating agent $\left(\mathrm{KNO}_{3}\right)$. Each spectrum was taken in the presence of $500 \mathrm{ppm}\left(2.8 \times 10^{-3} \mathrm{M}\right)$ MDAl.

shown in Fig. 3 (A shows spectra generated when $0.5 \mathrm{M}$ aggregating agent was used and B shows spectra generated when $1.0 \mathrm{M}$ aggregating agent was used). Every single peak that was present in the mean spectra was assigned a maximum and given defined start and end points (minimums). The peaks were then extracted and baseline corrected using an asymmetric least squares method. Although at this stage in the analysis it was not possible to clarify whether the bands present were the result of citrate scattering, MDAI scattering or in fact a combination of both.

Spectra collected from colloidal batches 2 and 3 generated no spectral features when combined with salts $1.0 \mathrm{M} \mathrm{KNO}_{3}$ and $0.5 \mathrm{M} \mathrm{KNO}_{3}$ respectively, repeat collections of the spectral data sets also proved unsuccessful, so these systems were omitted from further analysis. To interpret the optimum aggregation time for the systems, plots of peak area $v s$. time (s) were generated for each identified peak and manually assessed, with the objective of verifying the time at which the SERS signal reached a plateau. The time which was identified at the centre of the plateau region was designated as the optimum aggregation period. Identified times were then averaged across all the peaks identified in the individual systems. To generate values for peak area trapezoidal integration was used. This method splits the area under a peak into multiple trapezoidal components, from which the individual areas are calculated then summed giving an overall area value between the specified minima of a single peak. An example aggregation plot, demonstrating the position of the plateau region can be seen in Fig. 4 together with a table summarising the optimum aggregation times for all the colloidal batch variations.

\section{Reproducibility studies}

To study the reproducibility of SERS signal 5 replicates of each SERS system were used. In addition to the $40 \mathrm{~min}$ lag phase, each of the systems were allowed to aggregate for the defined optimum aggregation period after the salt solution was introduced. Spectra were analysed in a similar way as described previously except this time the relative standard deviations (RSDs) of each peak area were calculated and used to assess reproducibility between the different batches of sol. All peaks with a RSD $<15 \%$ were deemed reproducible and were tallied for each system. As the number of peaks present in the spectra of each of the systems appeared to vary quite significantly, the number of peaks $<15 \%$ were calculated as a percentage of the total number of peaks visible. One reason for the presence of so many different peaks in the spectra and the inability to assign them all to MDAI is due to the dynamic nature of the solution phase system. As the citrate stabilised nanoparticles are mixed 


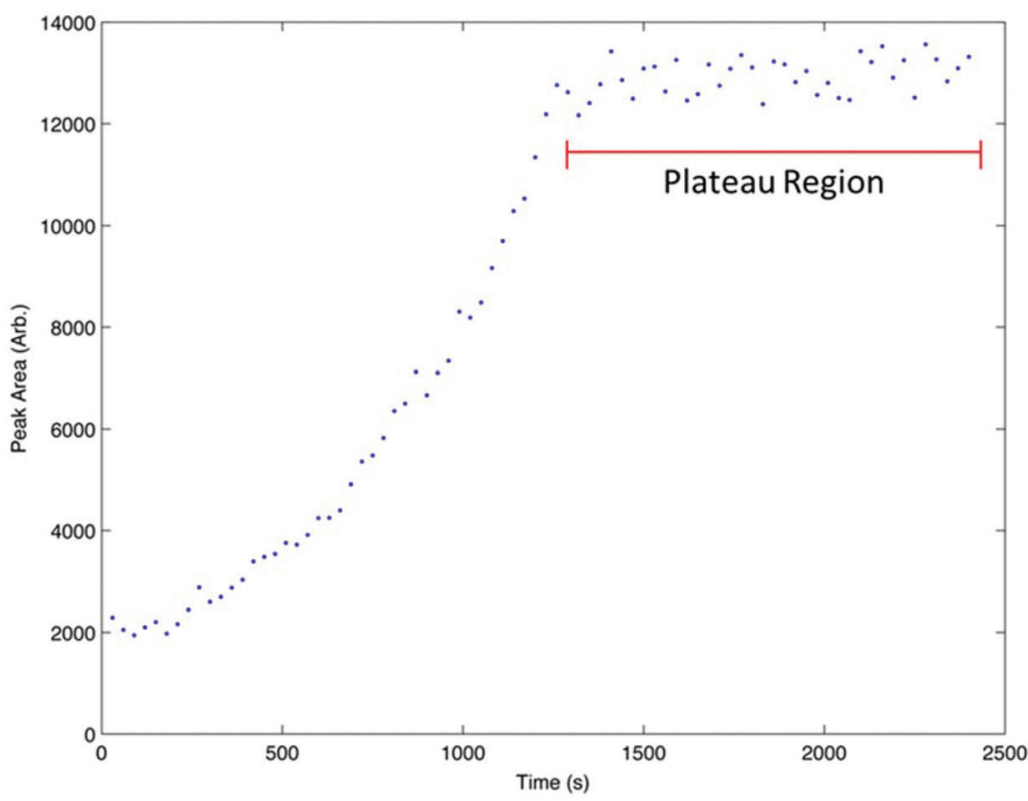

\begin{tabular}{|c|c|c|}
\hline Colloidal Batch $\mathbf{N}^{\mathbf{0}}$ & $\mathbf{K N O}_{\mathbf{3}} \mathbf{( M )}$ & Optimum Aggregation Time (s) \\
\hline 1 & 0.5 & 1800 \\
\hline 1 & 1 & 1650 \\
\hline 2 & 0.5 & 1860 \\
\hline 3 & 1 & 1000 \\
\hline 4 & 0.5 & 1700 \\
\hline 4 & 1 & 1600 \\
\hline 5 & 0.5 & 1500 \\
\hline 5 & 1 & 1400 \\
\hline
\end{tabular}

Fig. 4 An example plot of peak area versus time for the determination of optimum aggregation time. The plot was generated using the peak area at $1609 \mathrm{~cm}^{-1}$ using colloidal batch 1 and $0.5 \mathrm{M} \mathrm{KNO}_{3}$. The red line outlines the plateau region where the standard deviation relating to peak area is at its minimum. The time at the centre of this plateau region is estimated to be $1800 \mathrm{~s}$ or $30 \mathrm{~min}$, this is defined as the optimum aggregation time optimised aggregation times are detailed in the adjoining table for the different colloidal batches and respective salt concentrations.

into a solution of MDAI, the citrate and MDAI undergo rapid exchange on the surface. It is expected that MDAI would have a higher affinity for the silver due to it containing an amine group, therefore it is also expected that greater numbers of MDAI will eventually reside on the nanoparticles, than citrate. However, it must be remembered that neither citrate nor MDAI molecules are covalently bound to the nanoparticles, but instead are loosely associated; this 'association' along with the dynamic exchange also means that the orientation of the molecules on the surface is constantly changing. One advantage of carrying out these experiments in solution is the averaging effects achieved from Brownian motion and a large laser sampling volume; however, this does not mean that the individual systems will display exactly the same numbers of spectral features. Table 1 shows the results of the reproducibility testing and it is evident that colloidal batch 1 with $0.5 \mathrm{M}$ and $1.0 \mathrm{M} \mathrm{KNO}_{3}$ demonstrates the best reproducibility of all the batches with $71 \%$ and $69 \%$ of the peaks present displaying RSDs of $<15 \%$. Colloidal batch 4 combined with $1.0 \mathrm{M}$ of salt can be seen to have the worst reproducibility with only 1 peak in 16 having an RSD less than 15\%. Therefore the system which consisted of Batch 1 and $0.5 \mathrm{M}$ salt was used to establish the LOD of MDAI. Although it was initially thought that higher concentrations of $\mathrm{KNO}_{3}$ would hasten the aggregation time and effect reproducibility in some way, from this study no conclusions could be drawn as the effect this increase has on

Table 1 The reproducibility of the peaks present in each of the systems is assessed to find the best system. RSDs are assessed using the peak areas calculated for every single peak present in the 5 replicate spectra collected. Peaks with an RSD $<15$ were deemed acceptable

\begin{tabular}{lllll}
\hline & & \multicolumn{2}{l}{ Peaks present in spectra } \\
\cline { 3 - 5 } Colloidal batch no & $\mathrm{KNO}_{3}(\mathrm{M})$ & Total no & $\begin{array}{l}\text { No with } \\
\mathrm{RSD}<15\end{array}$ & $\begin{array}{l}\text { \% of peaks } \\
\text { with RSD }<15\end{array}$ \\
\hline 1 & 0.5 & 14 & 10 & 71 \\
1 & 1 & 13 & 9 & 69 \\
2 & 0.5 & 14 & 4 & 29 \\
3 & 1 & 16 & 5 & 31 \\
4 & 0.5 & 12 & 7 & 58 \\
4 & 1 & 16 & 1 & 6 \\
5 & 0.5 & 18 & 6 & 33 \\
5 & 1 & 16 & 8 & 50
\end{tabular}




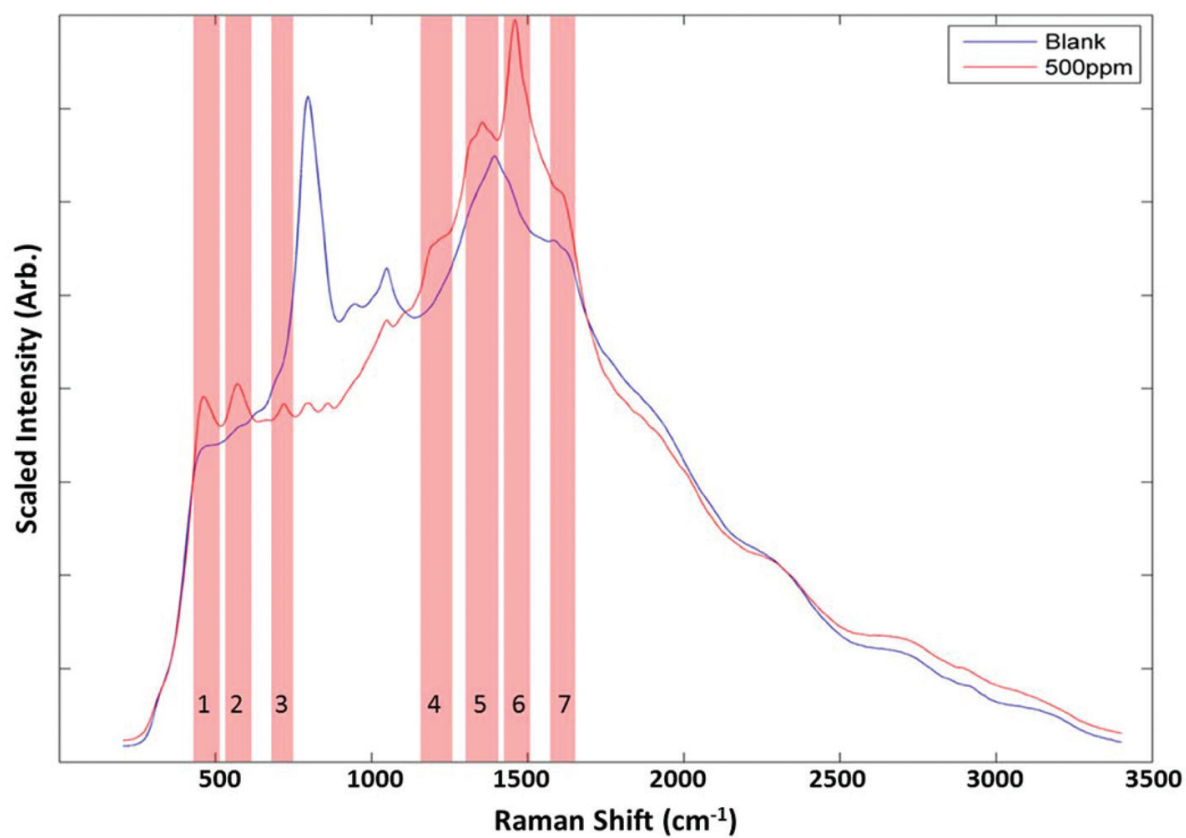

Raman Shift $\left(\mathrm{cm}^{-1}\right)$

Fig. 5 The plot shows a scaled overlay of SERS spectra for the optimised blank colloidal system in blue (colloidal batch $1,0.5 \mathrm{M} \mathrm{KNO}_{3}$ and no MDAI) with the optimised colloidal system containing MDAl in red (colloidal batch 1, $0.5 \mathrm{M} \mathrm{KNO}_{3}$, and 500 ppm MDAI). The peaks used for the LOD studies are highlighted by the red bands numbered 1-7. The peaks are positioned at $456 \mathrm{~cm}^{-1}, 565 \mathrm{~cm}^{-1}, 715 \mathrm{~cm}^{-1}, 1190 \mathrm{~cm}^{-1}, 1353 \mathrm{~cm}^{-1}, 1459 \mathrm{~cm}^{-1}$ and $1609 \mathrm{~cm}^{-1}$. At low concentrations of MDAl, the citrate peaks from $\sim 1100-1650 \mathrm{~cm}^{-1}$ appear more prevalent making it difficult to assign the MDAI peaks in this region.

the overall MDAI signal. The levels of variation in SERS signal seen with the differing batches of colloid are due to the difference in size and distribution of the synthesised nanoparticles. Work carried out previously within the group highlighted the variability of colloidal batches and in doing so also emphasised the need for careful assessment of the nanoparticles. ${ }^{25}$

\section{Limit of detection (LOD) studies}

When the concentration of MDAI was lowered it became evident which seven peaks in the spectra were representative of the analyte. Fig. 5 shows a mean blank spectrum $(200 \mu \mathrm{L}$ of colloidal batch $1,200 \mu \mathrm{L}$ of water and $50 \mu \mathrm{L}$ of $0.5 \mathrm{M} \mathrm{KNO}_{3}$ ) overlaid with a $500 \mathrm{ppm}$ SERS spectrum of MDAI $(200 \mu \mathrm{L}$ of colloidal batch 1, $200 \mu \mathrm{L}$ of $500 \mathrm{ppm}$ MDAI and $50 \mu \mathrm{L}$ of $0.5 \mathrm{M}$ $\mathrm{KNO}_{3}$ ). The red bands highlight the peaks in the plot from which the LOD of MDAI was established. Table 2 shows the LOD and band assignments for each of the peaks analysed. The LOD was estimated using the baseline corrected peak intensities at each concentration and by applying eqn (1). Where SD is the standard deviation of the colloidal blank, $c$ the intercept and $m$ the gradient. The SD of the colloidal blank was estimated using the same peak positions and intensities used when MDAI was present.

$$
\mathrm{LOD}=\frac{((3 \times \mathrm{SD} \text { of blank }) \pm c)}{m}
$$

The LODs calculated for the 7 peaks identified ranged from $\sim 20$ to $6 \mathrm{ppm}\left(1.42 \times 10^{-5} \mathrm{M}\right.$ to $\left.3.19 \times 10^{-4} \mathrm{M}\right)$. The average
Table 2 Tentative SERS vibrational assignments for the 7 peaks identified for MDAI

\begin{tabular}{lll}
\hline $\begin{array}{l}\text { Peak position } \\
\left(\mathrm{cm}^{-1}\right)\end{array}$ & Assignment & $\begin{array}{l}\text { Estimated LOD } \\
(\mathrm{M})\end{array}$ \\
\hline 456 & $\begin{array}{l}\text { Unassigned } \\
565\end{array}$ & $\begin{array}{l}\text { Unassigned } \\
\text { Substituted benzene }\end{array}$ \\
715 & $\begin{array}{l}3.19 \times 10^{-5} \\
\text { deformation }\end{array}$ \\
1190 & $\begin{array}{l}\text { C-N stretch or dioxolane ring } \\
\text { vibration }\end{array}$ & $1.40 \times 10^{-5}$ \\
& $\begin{array}{l}\text { Unassigned } \\
1353\end{array}$ & $4.53 \times 10^{-4}$ \\
1459 & $\begin{array}{l}1,2,4,5-\text { tetrasubstituted benzene } \\
\text { vibration }\end{array}$ & $5.31 \times 10^{-5}$ \\
1609 & C=C aromatic stretch & $3.75 \times 10^{-5}$ \\
& &
\end{tabular}

LOD estimated from all the peaks was $8 \mathrm{ppm}\left(5.4 \times 10^{-5} \mathrm{M}\right)$. Example LOD plots are displayed in Fig. 6. Fig. S2 $\uparrow$ shows mean spectra collected at each MDAI concentration down to the LOD (including a colloidal blank).

\section{Conclusion}

In this study it has been demonstrated that SERS can be used to detect the presence of MDAI in solutions at concentrations lower than previously reported methods of $200 \mathrm{ppm}$ by microcrystalline testing. ${ }^{18}$ It has also been shown that signal vari- 

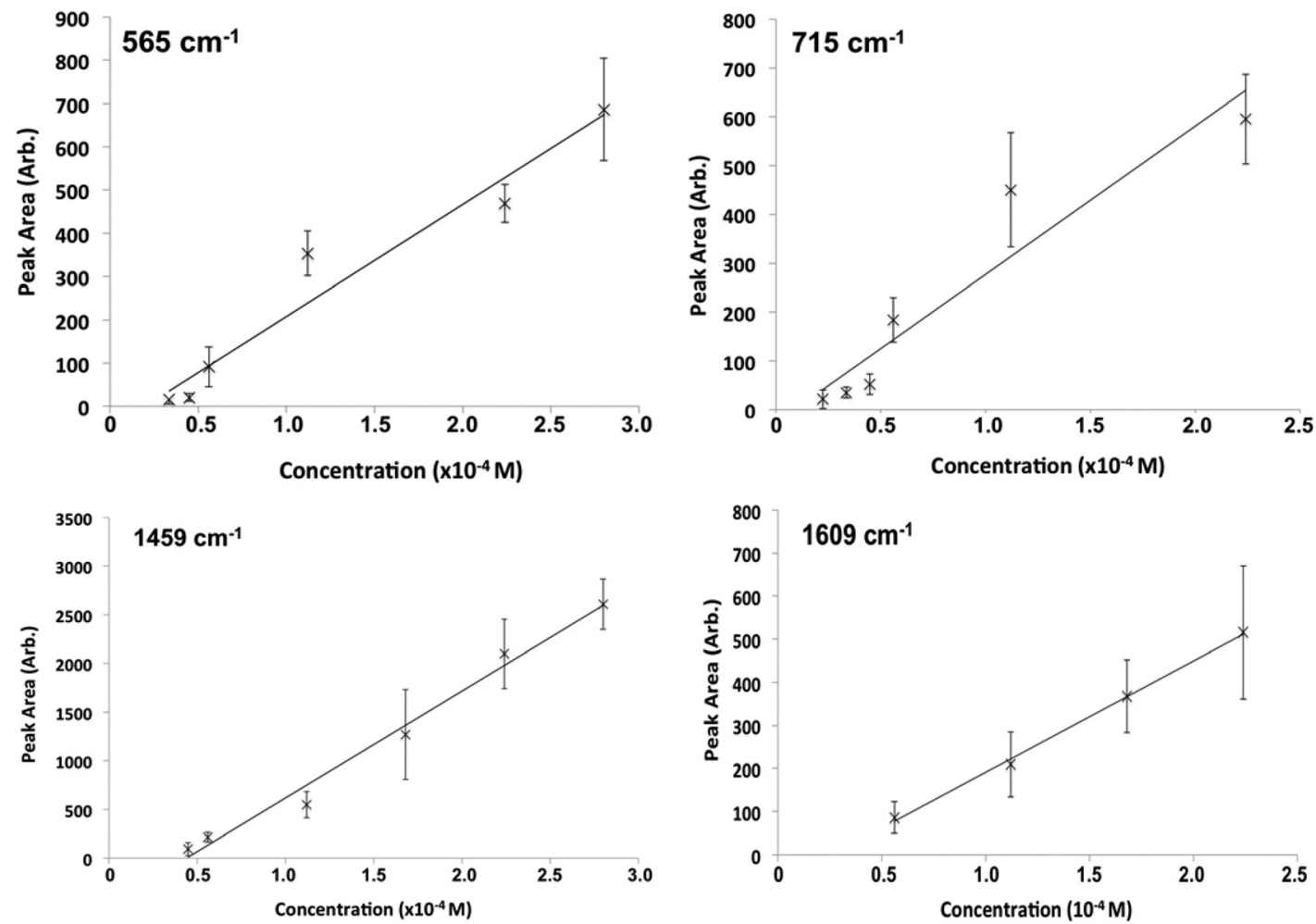

Fig. 6 Example plots of peak area versus concentration for the four of the seven identified MDAl peaks. The $y$ axes represent peak area (Arb.) whilst the $x$ axes represent the concentration of MDAI $\left(\times 10^{-4} \mathrm{M}\right)$. Whilst higher concentrations of MDAI were easy to distinguish, it is believed that the drug at these concentrations completely saturated the colloid surface, making the SERS signal non-linear with respect to concentration, therefore only the linear range is plotted.

ations can occur between different batches of silver sol synthesised using the same preparative methods, and this emphasises the need for optimisation in order to improve signal reproducibility. A technique's reproducibility and sensitivity ultimately influences its widespread usage in the analytical field, so optimisations like the ones carried out here are important. The optimised SERS method was also demonstrated to be clearly quantitative and the typical limit of detection for MDAI was $5.4 \times 10^{-5} \mathrm{M}$. Overall a cheap, facile, sensitive and reproducible method for the detection of a substance has been produced. Moreover, due to the ready portability of Raman spectroscopy and SERS this approach could be deployed in the field. Further work would involve the evaluation of the discriminatory properties of such an optimised system, which we have previously reported for other drugs containing the same structural moieties using chemometric methods. ${ }^{26}$

\section{Acknowledgements}

SM and RG would like to thank the ESPRC and ACTF. We are also grateful to Will Greenwood, Rabica Mohib Kazmi, Deepna Shah and Rebecca Turner for their help with SERS optimization.

\section{References}

1 European Monitoring Centre for Drugs and Drug Addiction (EMCDDA), Europol 2010 Annual Report on the implementation of Council Decision 2005/387/JHA, http://www.emcdda. europa.eu/publications/implementation-reports/2010, accessed 24th July 2012.

2 European Monitoring Centre for Drugs and Drug Addiction (EMCDDA), Europol 2011 Annual Report on the implementation of Council Decision 2005/387/JHA, http://www.emcdda. europa.eu/publications/implementation-reports/2011, (Retrieved 24th July 2012).

3 A. R. Winstock, P. Griffiths and D. Stewart, Drugs and the dance music scene: A survey of current drug use patterns among a sample of dance music enthusiasts in the UK, Drug Alcohol Depen., 2001, 64, 9.

4 5-IAI. Benzo-fury.me.uk, http:/www.benzo-fury.me.uk/ index/3, (Retrieved 24th March 2012).

5 Benzofury, 5-APB and 6-APB. Benzofury.com, http://www. benzofury.com/en/search?tag=Benzo+Fury (Retrieved $13^{\text {th }}$ June 2012).

6 Buy MDAI Gold (Sparkle). Vip-legals.com, http://vip-legals. com/mdai-gold, (retrieved 20th July 2012).

7 R. P. Archer, R. Treble and K. Williams, Reference materials for new psychoactive substances, Drug Test. Anal., 2011, 3, 505 . 
8 C. T. Gallagher, S. Assi, J. L. Stair, S. Fergus, O. Corazza, J. M. Corkery and F. Schifano, 5,6-Methylenedioxy-2aminoindane: from laboratory curiosity to 'legal high', Hum. Psychopharmacol., 2012, 27, 106.

9 F. Schifano, A. Albanese, S. Fergus, J. L. Stair, P. Deluca, O. Corazza, Z. Davey, J. Corkery, H. Siemann, N. Scherbaum, M. Farre, M. Torrens, Z. Demetrovics and A. H. Ghodse, Mephedrone (4-methylmethcathinone; 'meow meow'): chemical, pharmacological and clinical issues, Psychopharmocology, 2011, 214, 593.

10 Legal drug mephedrone could have devastating side effects, The Journal http://www.journallive.co.uk/north-east-news/ todays-news/2009/11/27/legal-drug-mephedrone-couldhave-devastating-side-effects-61634-25264054, (published 27th November 2009, retrieved 14th May 2011).

11 E. Saner, Mephedrone problem: Legal highs,The Guardian, http://www.guardian.co.uk/society/2009/dec/05/mephedroneproblem-legal-highs, (Published $5^{\text {th }}$ December 2009, accessed $8^{\text {th }}$ August 2008).

12 ACMD (Advisory Council on the Misuse of Drugs), Consideration of the Cathinones, http://www.homeoffice.gov. uk/publications, (accessed August 10, 2012).

13 D. E. Nichols, W. K. Brewster, M. P. Johnson, R. Oberlender and R. M. Riggs, Non Neurotoxic Tetralin and Indan Analogues of 34-Methylenedioxyamphetamine (MDA), Med. Chem., 1990, 33, 703.

14 J. E. Sprague, M. P. Johnson, C. J. Schmidt and D. E. Nichols, Studies on the mechanism of p-chloroamphetamine neurotoxicity, Biochem. Pharmacol., 1996, 52, 1271.

15 M. P. Johnson, P. F. Conarty and D. E. Nichols, [3H]monoamine releasing and uptake inhibition properties of 3,4methylenedioxymethamphetamine and p-chloroamphetamine analogues, Eur. J. Pharmacol., 1991, 23, 9.
16 Department of Health: Isle of Man, Isle of man bans so called legal high MDAI, http://www.manx.net/isle-of-mannews/4099/isle-of-man-bans-so-called-legal-high-mdai, (Published $14^{\text {th }}$ December 2011, accessed $8^{\text {th }}$ August 2012.

17 A. Wohlfarth and W. Weinman, Bioanalysis of new designer drugs, Bioanalysis, 2010, 2, 965.

18 L. Elie, M. Baron, R. Croxton and M. Elie, Microcrystalline Identification of Selected Designer Drugs, Forensic Sci. Int., 2012, 214, 182.

19 J. F. Casale and P. A. Hays, The characterization of $\alpha$-pyrrolidinopentiophenone, Microgram J., 2012, 9, 33.

20 E. C. Le Ru, E. Blackie, M. Meyer and P. G. Etchegoin, Surface Enhanced Raman Scattering Enhancement Factors: A Comprehensive Study, J. Phys. Chem. C, 2007, 111, 13794.

21 M. Moskovits, Surface-Enhanced Raman Spectroscopy: a Brief Perspective in Surface-Enhanced Raman Scattering: Physics and Applications, ed. K. Kneipp, M. Moskovits and H. Kneipp, Springer, Berlin, 2006, pp. 1-18.

22 Medicines Act 1968 Chapter 67, http://www.legislation.gov. uk/ukpga/1968/67 (accessed 20th July 2012).

23 P. C. Lee and D. Meisel, Adsorption and Surface-Enhanced Raman of Dyes on Silver and Gold Sols, J. Phys. Chem., 1982, 86, 3391.

24 UK is Europe's 'addictions capital', says think tank, $B B C$, http://www.bbc.co.uk/news/uk-23913818, (Published 1st September 2013, accessed $3^{\text {rd }}$ September 2013).

25 S. Mabbott, E. Correa, D. P. Cowcher, J. W. Allwood and R. Goodacre, Optimization of Parameters for the Quantitative Surface-Enhanced Scattering Detection of Mephedrone Using a Fractional Factorial Design and a Portable Raman Spectrometer, Anal. Chem., 2013, 85, 923.

26 S. Mabbott, A. Eckmann, C. Casiraghi and R. Goodacre, 2p or not 2p: tuppence-based SERS for the detection of illicit materials, Analyst, 2013, 138, 118. 